\title{
An Examination of the Relationships Among Appreciation, Gratitude, and Happiness
}

\author{
Nicholas J. Wolf \\ Irvine Valley College (CA) \\ Suggested bibliographic reference \\ Wolf, N. J. (2021). An examination of the relationships among appreciation, gratitude, and happiness. \\ Psi Beta Journal of Research, 1(1), 41-45. https://doi.org/10.54581/WUUA9555
}

\begin{abstract}
The purpose of the present study was to examine the relationships among appreciation, gratitude, and happiness - particularly the emotional components of positive affect, negative affect, and life satisfaction. Several hypotheses were posed. It was expected that there would be positive relationships among appreciation and gratitude in relation to happiness, positive affect, and life satisfaction. It was also expected that appreciation and gratitude would be negatively related to negative affect. Seventy-seven participants (22 males and 55 females) in various psychology courses at a community college participated in an online survey for course credit. The results replicated findings from previous research and showed support for all the hypotheses in the present study. Specifically, appreciation and gratitude were positively related to an individual's overall happiness, positive affect, and life satisfaction. Results also showed that appreciation and gratitude were inversely related to negative affect. These results suggest the impact being appreciative and grateful has on one's emotional health and quality of life. As such, these results have the potential to help individuals cope with lower emotional functioning by helping them focus on the positive aspects of their life experiences.
\end{abstract}

Keywords: appreciation, gratitude, happiness, life satisfaction

The act of being appreciative and grateful, or lack thereof, may have significant influence on one's overall happiness, emotional health, and life satisfaction. Appreciation occurs when someone acknowledges the value or meaning of something in a positive way (Adler, 2002); gratitude is the positive feeling someone experiences after something good happens to them or something is given to them (Adler \& Fagley, 2005). Researchers have found that one cannot experience gratitude without appreciation, yet appreciation can occur without gratitude (Tucker, 2007). For example, one can witness a kind act, such as seeing someone get help loading their groceries into their car, which would result in one having appreciation for that event yet have no feeling of gratitude for it because it was not personally relevant to them. If the individual was the one receiving the help, then a feeling of gratitude would result because the act of help is received personally. Watkins et al. (2003) showed the interconnectedness of these two concepts, and that people who are grateful tend to appreciate simple pleasures in life, such as walking outside and feeling the sunshine on one's face. Other examples of simple pleasures are finding comfort in knowing one has a bed to sleep in, 
clean running water to bathe and drink, and food to eat. However, despite the concepts of appreciation and gratitude being similar, few studies have investigated appreciation. Over the years, many studies focused primarily on gratitude; these studies generally involve the emotional factor of happiness.

Research conducted on all three concepts (appreciation, gratitude, and happiness) has shown positive relationships among these concepts (Abbe et al., 2003; Adler \& Fagley, 2005; Tucker, 2007). It has been found that happiness involves both appreciation and gratitude, in part in how individuals react to and perceive life events (Diener, 2000). The happier the person is, the more appreciative they are and the unhappier the person is, the less appreciative. For example, one study found that happier individuals have greater appreciation for rewarding events, whether these events be real-life or hypothetical (Tucker, 2007). Researchers have also found that individuals who are both grateful and appreciative are generally happier (Tucker, 2007; Watkins et al., 2003). Other researchers have found that if an individual practices expressing gratitude (Watkins et al., 2003) they can increase their happiness (Abbe et al., 2003; Lyubomirsky, 2007). Researchers have also found a significant relationship between gratitude and life satisfaction (Adler \& Fagley, 2005; McCullough et al., 2002; Ramzan \& Rana, 2014). Just as grateful people are happier, they also tend to be more satisfied with their lives (Tucker, 2007).

Appreciation and gratitude have been found to relate to an emotional component of happiness positive affect. Specifically, there are positive relationships among appreciation, gratitude, and positive affect (see Diener, 1984; Diener, 2000). Numerous studies have found positive relationships between gratitude and positive affect (Ramzan \& Rana, 2014; Tucker, 2007; Watkins et al., 2003). Additionally, one study found that individuals who claimed to regularly experience gratitude have greater positive affect and well-being in their lives, and that being grateful had a significant relationship with the individual's positive affectivity (McCullough et al., 2002).

In addition to positive affect, appreciation and gratitude have been found to be related to negative affect. Ramzan and Rana (2014) found that there is a negative relationship between gratitude and negative affect, and that participants who revealed more depressive symptoms were lower in gratitude. Also, it has been found that if someone lacks gratitude, they are more prone to developing mental health issues such as anxiety and/or depression (McCullough et al., 2002). These results reveal the impact that lacking gratitude may have on an individual's life and overall emotional health.

The purpose of the present study was to examine the relationships among appreciation, gratitude, happiness and the emotional components of positive affect, negative affect, and life satisfaction. Several hypotheses were posed: It was expected that there would be positive relationships among appreciation and gratitude in relation to happiness, positive affect, and life satisfaction. It was also expected that appreciation and gratitude would be inversely related to negative affect.

\section{Method and Procedure}

A correlational design was used to test the posed hypotheses. After receiving approval by the Institutional Review Board, participants were recruited from various psychology classes at a community college to complete an online survey for course credit. Participants completed informed consent forms prior to taking the survey which ensured their anonymity throughout the entire research process. A total of eighty-seven participants (23 males and 64 females) completed the survey. The data were collected over a period of five days.

\section{Measures}

Participants indicated their sex by selecting male or female and their age by typing in a numerical value. Appreciation was measured using the General Appreciation Scale (GAS; Tucker, 
2007), which includes five statements and measures one's general level of appreciation; participants were asked to indicate how true each statement was to them using a 7-point Likert scale $(1=$ not at all true of me; 7 = extremely true of $m e)$. Gratitude was measured using the Gratitude Questionnaire-Six Item Form (GQ-6; McCullough et al., 2002), which includes six statements; using a 7-point Likert scale $(1=$ strongly disagree; 7 = strongly agree) participants indicated which best described themselves. Happiness was measured using the Subjective Happiness Scale (SHS; Lyubomirsky \& Lepper, 1999), which has four items; participants were asked to indicate which statements best described themselves using a 7-point Likert scale $(1=$ not a very happy person; $7=a$ very happy person). Affectivity was measured using the Positive and Negative Affect Schedule (PANAS; Watson et al., 1988), which contains twenty items used to measure an individual's general level of mood; using a 7-point Likert scale (1 $=$ very slightly; $7=$ extremely) participants were asked to indicate the extent to which they felt each item in general. Life satisfaction was measured using the Satisfaction with Life Scale (SWLS; Diener et al., 1985), which has five items and asks participants to indicate the extent to which each statement is true for them using a 7-point Likert scale $(1=$ strongly disagree; $7=$ strongly agree $)$.

\section{Results}

All hypotheses were tested using the Pearson Product-Moment Correlation Coefficient. Prior to final data analysis, ten participants were removed from the data set because nine were underage and researchers did not gain parental consent and one had an apparent response set (i.e., a participant responded with the same number regardless of the question which would have reduced the data's reliability). These factors resulted in a sample of seventy-seven participants (22 males and 55 females) for data analysis. Reverse coding was performed on the third and last items of the GQ-6 and the last item of the SHS.

\section{Table 1}

Descriptive Statistics and Correlations for Study Variables

\begin{tabular}{lccccc}
\hline \multicolumn{1}{c}{ Variable } & $N$ & $M$ & $S D$ & $A P P R$ & GRAT \\
\hline Appreciation & 77 & 5.17 & 1.15 & -- & -- \\
Gratitude & 77 & 5.29 & 0.98 & -- & -- \\
Happiness & 77 & 4.47 & 1.28 & $.55^{* *}$ & $.49^{* *}$ \\
Positive Affect & 77 & 4.82 & 1.04 & $.58^{* *}$ & $.43^{* *}$ \\
Negative Affect & 77 & 3.30 & 1.32 & $-.37^{* *}$ & $-.26^{* *}$ \\
Life Satisfaction & 77 & 4.33 & 1.46 & $.62^{* *}$ & $.53^{* *}$ \\
\hline
\end{tabular}

$* \mathrm{p}<.05 . * * \mathrm{p}<.01$

Data analysis found several significant relationships across all hypotheses (see Table 1 for descriptives and correlations on each of the primary variables). There were positive relationships shown between appreciation and happiness, $r(75)$
$=.55, p<.001$, appreciation and positive affect, $r(75)=.58, p<.001$, and appreciation and life satisfaction, $r(75)=.62, p<.001$. Also, there were positive relationships shown between gratitude and happiness, $r(75)=.49, p<.001$, gratitude and 
positive affect, $r(75)=.43, p<.001$, and gratitude and life satisfaction, $r(75)=.53, p<.001$. Additionally, negative relationships were shown between appreciation and negative affect, $r(75)=$ $.37, p<.001$ and gratitude and negative affect, $r(75)=-.26, p<.05$.

\section{Discussion}

Results showed support for all hypotheses in the present study. Participants who scored high on appreciation and gratitude also scored high on happiness, positive affect, and life satisfaction. Those who scored low on appreciation and gratitude scored low on happiness, positive affect, and life satisfaction. Also, the participants who scored low on appreciation and gratitude scored high on negative affect, and those who scored high on appreciation and gratitude scored low on negative affect.

These results align well with findings of previous research. Tucker (2007) found significant positive relationships among appreciation, happiness, positive affect, and life satisfaction. The results are also consistent with the relationships found by other researchers when studying gratitude and happiness and its emotional components of positive affect, negative affect, and life satisfaction (McCullough et al., 2002; Ramzan \& Rana, 2014). These results suggest that appreciation and gratitude have an influential impact on the overall quality of an individual's emotional functioning and quality of life. It is possible that participants who scored high on appreciation, gratitude, positive affect, and life satisfaction have a greater desire to live a life of happiness. This potential desire to be happy and experience satisfaction with life may be the reason why these individuals are generally more appreciative and grateful; that is, it is possible that motivation for happiness and life satisfaction is an underlying factor for these results. In fact, research done by Lyubomirsky (2007) supports the notion that there may be a link between such motivation and achieving and sustaining happiness. This motivational factor of desiring happiness could also be linked to appreciation and gratitude.

Related to some type of happiness motivation, Maslow (1943) postulated his hierarchy of needs theory that proposed there is a human drive for individuals to fulfill different needs throughout their life. Once lower needs are fulfilled (i.e., basic physiological needs, safety, sex, social belonging, esteem), humans are then motivated to strive for the highest need, self-actualization, which involves the meaning of human existence and life (Funder, 2016). It could be that happiness is involved in achieving this higher selfactualization need. In fact, it may be that appreciation and gratitude are associated motivational factors which enhance one's ability to achieve this higher need.

These results are important because they suggest the impact being appreciative and grateful impacts one's emotional health and quality of life. It seems that appreciation and gratitude serve as key components for living a happy, satisfying, and fulfilling life. Additionally, it could be that these two constructs have the potential to help those experiencing lower levels of emotional function-ing, and suggests coping strategies (e.g., practice enjoying the simple pleasures in life, writing a daily gratitude list, being thankful for the little things; see Lyubomirsky, 2007) to help combat negative emotional symptoms. Further-more, it is possible that these results may also be beneficial on a societal scale and could lead to an overall happier society. It has been found that happy people engage in more prosocial behavior (Lyubomirsky, 2007); if more individuals within a society were more appreciative, grateful, and happy, then perhaps a gradual movement toward positive, helpful behavior would take place resulting in higher quality of societal life.

Although the present results align well with previous research and provide practical implications, it is appropriate to address that this study was not without limitations. First, the study was conducted using participants of a younger population with an average age of twenty years old. Giv- 
en this sample, this study cannot be generalized to older populations; however, it is suspected that the inclusion of older age groups would reveal similar correlations because appreciation, gratitude, and happiness appear to be stable across time and situations (see Lyubomirsky, 2007). Second, only one scale, the General Appreciation Scale (Tucker, 2007), was used to measure appreciation. The GAS is intentionally designed as a general measure. Therefore, future research could investigate more specific aspects of appreciation by examining the construct in terms of different categories (e.g., friends, family, workplace, etc.). Additionally, it would be beneficial to further examine appreciation in relation to one's happiness and satisfaction with life. Considering the implications of this study's results, future research should aim to further deepen our understanding of the underlying mechanisms, such as motivation, for the relationships that exist among appreciation, gratitude, and happiness.

\section{References}

Abbe, A., Tkach, C., \& Lyubomirsky, S. (2003).

The art of living by dispositionally happy people. Journal of Happiness Studies, 4(4), 385404.

https://doi.org/10.1023/B:JOHS.0000005769.5 $4611.3 \mathrm{c}$

Adler, M. G. (2002). Conceptualizing and measuring appreciation: The development of a new positive psychology construct (Publication No. 3062466). [Doctoral dissertation, Rutgers The State University of New Jersey]. ProQuest Dissertations and Theses Global.

Adler, M. G., \& Fagley, N. S. (2005). Appreciation: Individual differences in finding value and meaning as a unique predictor of subjective well-being. Journal of Personality, 73(1), 79114. https://doi.org/10.1111/j.14676494.2004.00305.x

Diener, E. (1984). Subjective well-being. Psychological Bulletin, 95(3), 542-575. https://doi.org/10.1037/00332909.95.3.542
Diener, E. (2000). Subjective well-being: The science of happiness and a proposal for a national index. American Psychologist, 55(1), 34-43. https://doi.org/10.1037/0003-066X.55.1.34

Diener, E., Emmons, R. A., Larsen, R. J., \& Griffin, S. (1985). The satisfaction with life scale. Journal of Personality Assessment, 49(1), 7175. https://doi.org/10.1207/s15327752jpa4901_13 Funder, D. C. (2016). The personality puzzle. In K. Barton \& S. Snavely (Eds.), Experience, existence, and the meaning of life: Humanistic and positive psychology (7th ed., pp. 422-455). W.W. Norton \& Company.

Lyubomirsky, S. (2007). The how of happiness: A new approach to getting the life you want. Penguin Group.

Lyubomirsky, S., \& Lepper, H. (1999). A measure of subjective happiness: preliminary reliability and construct validation. Social Indicators Research, 46(2), 137-155. https://doi.org/10.1023/A:1006824100041

McCullough, M. E., Emmons, R. A., \& Tsang, J. A. (2002). The grateful disposition: a conceptual and empirical topography. Journal of Personality and Social Psychology, 82(1), 112-127. https://doi.org/10.1037/0022-

3514.82.1.112

Ramzan, N., \& Rana, S. A. (2014). Expression of gratitude and subjective well-being among university teachers. Indian Journal of Positive Psychology, 5(4), 363-367. https://doi.org/10.15614/ijpp.v5i4.1212

Tucker, K. L. (2007). Getting the most out of life: An examination of appreciation, targets of appreciation, and sensitivity to reward in happier and less happy individuals. Journal of Social and Clinical Psychology, 26(7), 791-825. https://doi.org/10.1521/jscp.2007.26.7.791 